\title{
Estruturas de Governança e Recursos Estratégicos: um estudo sobre a capacidade de resposta às leis ambientais em destilarias no estado do Paraná
}

\author{
Cleiciele Albuquerque Augusto ${ }^{1}$ e José Paulo de Souza ${ }^{2}$
}

Resumo: Este artigo tem o objetivo de compreender como as estruturas de governança, configuradas por recursos estratégicos, podem afetar a capacidade de resposta às leis ambientais, nas relações de produtores e processadores, em destilarias paranaenses. Para tanto, a partir de uma perspectiva complementar das abordagens da Economia dos Custos de Transação (ECT) e Visão Baseada em Recursos (VBR), realizou-se uma pesquisa qualitativa do tipo descritiva, contemplando entrevistas semiestruturadas com gerentes agrícolas e fornecedores de 5 das 7 destilarias presentes no estado do Paraná. Os resultados indicaram o contrato de parceria do tipo arrendamento como o mais adequado para otimizar o atendimento das destilarias às leis ambientais, devido ao controle total obtido sobre o processo produtivo. Os contratos de parceria agrícola e fornecimento podem demandar mais tempo, pois envolvem a coordenação da relação da destilaria com seus contratados. A complementaridade entre estruturas de governança (ECT) e recursos estratégicos (VBR), foco do presente estudo, é ratificada a partir da consideração de que os recursos estratégicos das destilarias, tais como localização, distância, conhecimento, entre outros, influenciam na escolha de estruturas de governança, cuja orientação se define, notadamente, pela preferência de arranjos na forma híbrida ou integrados verticalmente. Essas estruturas, por sua vez, são escolhidas para explorar, proteger e obter vantagens competitivas por meio do controle obtido sobre esses recursos.

Palavras-chaves: Estruturas de governança, recursos estratégicos, complementaridade entre ECT e RBV, capacidade de resposta às leis ambientais, destilarias paranaenses.

Abstract: This paper aims to understand how the structures of governance, settled by strategic resources, may affect responsiveness to environmental laws, the relations of producers and processors, in distilleries of Paraná. From a complementary perspective of Transaction Costs Economics (TCE) and Resource Based View (RBV) approaches, a qualitative and descriptive research, with cross-sectional and longitudinal perspective, was

1 Doutoranda em Administração pela Universidade Federal de Santa Catarina (CPGA/UFSC). E-mail: cleicielealbuquerque@yahoo.com.br

2 Professor associado do Departamento de Administração e do Programa de Pós-graduação em Administração da Universidade Estadual de Maringá (DAD/PPA/UEM). E-mail: jpsouza@uem.br 
conducted. The study involved semi-structured interviews with five managers and agricultural producers engaged in distilleries located in Paraná state. Results indicated partnership in the lease form as the most appropriate to optimize the responsiveness to environmental laws, because of the total control obtained regarding the manufacturing process. The farming partnership and supply contract may require more time, because involves the coordination of the relationship of the distillery with its contractors. Complementarity between governance structures (TCE) and strategic resources $(R B V)$, the focus of this study is ratified from the consideration that internal resources and capabilities of distilleries, such as location, distance, knowledge and others influence the choice of more vertically integrated governance structures. These, in turn, are chosen to explore, protect and obtain competitive advantage through the control over those resources.

Key-words: Governance structures, strategic resources, TCE and RBV complementarity, responsiveness to environmental laws, distilleries in Paraná.

Classificação JEL: L14.

\section{Introdução}

Nos últimos anos, os biocombustíveis ganharam notoriedade e a produção brasileira de álcool tem ocupado posição de destaque no cenário internacional. O estado do Paraná, neste contexto, ocupa a posição de segundo maior produtor nacional de álcool, apresentando perfil moderno e sendo superado, nesse aspecto, apenas pelo estado de São Paulo (LINS e SAAVEDRA, 2007). De acordo com dados da Alcopar (2010), no período de 2002 a 2009, houve aumento de 52\% na área utilizada para o plantio de cana-de-açúcar no Paraná, o que significou acréscimo de 90,2\% da produção de álcool paranaense.

Frente a esse crescimento, o setor alcooleiro tem sido apontado como um impulsionador do desenvolvimento econômico, em função dos benefícios que tem propiciado. Por outro lado, ele tem sido criticado pela degradação que as atividades inerentes à fabricação do álcool causam ao meio ambiente. Tendo-se em vista que a produção de álcool não envolve apenas um segmento, existindo uma relação de interdependência entre produtores e processadores, surge um problema de coordenação. Essa coordenação se dá por meio de estruturas de governança que sejam capazes de minimizar os custos de transação envolvidos.

Tradicionalmente, as estruturas de governança têm sido estudadas por abordagens da Nova Economia Institucional (NEI), especialmente pela
Economia dos Custos de Transação (ECT), a partir dos trabalhos de Coase (1937), Williamson (1975, 1985, 1996), Klein, Crawford e Alchian (1978). Entretanto, estudos mais recentes têm buscado na abordagem da Visão Baseada em Recursos (VBR), fundamentada nos estudos de Penrose (1959), Wernerfelt (1984), Barney (1991) e Peteraf (1993), aspectos complementares na configuração dessas estruturas, visando responder algumas limitações na explicação das fronteiras da empresa.

Discussões sobre a complementaridade entre as duas abordagens têm sido percebidas nos trabalhos de Langlois (1992), Ghoshal e Moran (1996), Poppo e Zenger (1997), Combs e Ketchen (1999), Williamson (2002), Foss e Foss (2001; 2004), Jacobides e Winter (2005), Argyres e Zenger (2008) e Saes (2009). Segundo esses autores, a ECT e a VBR trabalham com fenômenos sobrepostos e, muitas vezes, complementares. Isso porque a história da firma, os seus recursos e capacidades, aspectos trabalhados pela VBR, influenciam na escolha da estrutura de governança adequada e nos limites da firma, questões tratadas pela ECT.

Essa discussão se torna relevante a partir da constatação de Argyres e Zenger (2008) de que existe uma falsa dicotomia entre a ECT e a VBR, uma vez que a ECT, devidamente compreendida, é preocupada com a questão de quais estruturas de governança (mercado, contratos ou integração vertical) facilitam o desenvolvimento de recursos e capacidades e permitem sua melhor exploração, 
dada a presença de incertezas e possíveis comportamentos oportunistas. Portanto, os autores defendem que

[...] os estudiosos devem tratar considerações sobre capacidades como inextricavelmente entrelaçadas com a lógica dos custos de transação, e devem procurar analisar os aspectos desta complexa interação (ARGYRES e ZENGER, 2008, p. 29, tradução nossa).

Sendo assim, a seguinte questão de pesquisa é apresentada: Como as estruturas de governança, configuradas por recursos e capacidades diferenciadas, podem afetar a capacidade de resposta aos estímulos impostos pelo aparato legal ambiental, nas relações de produtores e processadores, em destilarias no estado do Paraná? As evidências quanto à importância de se entender as problemáticas transacionais entre produtor e processador, no atendimento à legislação ambiental do setor, envolvendo conhecimento técnico, dependência e garantias de direito de propriedade, e aquelas de relevância teórica, citadas acima, definem a validade e o caráter inovador do presente estudo.

Nessa orientação, a resposta à pergunta apresentada indicou, inicialmente, a necessidade de se descrever como as leis ambientais interagem com a dinâmica operacional, envolvendo produtores e processadores, nas destilarias pesquisadas. Em um segundo momento, buscou-se apresentar os tipos de estruturas de governança adotadas e como elas definem condições operacionais especificas às atividades das destilarias e dos produtores estudados. Em seguida, a preocupação foi identificar os recursos estratégicos das destilarias pesquisadas e descrever como eles podem influenciar na configuração das estruturas de governança. Por fim, buscou-se compreender como as estruturas de governança, configuradas por recursos e capacidades diferenciadas, podem afetar a capacidade de resposta aos estímulos impostos pelo aparato legal ambiental, nas relações de produtores e processadores, em destilarias no estado do Paraná.
Para atingir os objetivos propostos, o trabalho apresenta, além desta introdução, uma seção que contempla o referencial teórico utilizado, discutindo a ECT e a VBR em termos de características principais e aspectos complementares; outra seção apresenta os resultados alcançados; uma última seção registra as considerações finais obtidas e as referências utilizadas.

\section{Referencial teórico}

\subsection{Economia dos custos de transação}

De acordo com Langlois e Foss (1997), a ECT surgiu com Ronald Coase, que introduziu em seu célebre artigo "The nature of the firm", em 1937, uma nova perspectiva para o entendimento das estratégias empresariais ao mostrar que existem custos, além dos custos de produção, associados ao funcionamento dos mercados: os custos de transação. Para Zylbersztajn (2009), Coase introduziu uma mudança de paradigma na teoria econômica, implantando um novo marco teórico, ao discutir

as razões explicativas para a existência da firma com base nos custos comparativos da organização interna e de produção via mercado, lançando as bases para o estudo das formas alternativas de organização das firmas contratuais (p. 42).

Nas décadas de 1970 e 1980, a partir dos trabalhos realizados por Coase (1937) e Williamson (1985), impulsiona-se a questão dos custos de transação e estruturas de governança dentro da literatura econômica. Na visão de Williamson (1996), as estruturas de governança são mecanismos de coordenação empregados para reduzir custos de transação na realização das transações, a partir de instituições reguladoras. As instituições são as regras do jogo e, junto às regras da economia, definem o conjunto de escolhas presentes para as organizações (NORTH, 1991).

De acordo com Zylbersztajn (2009), as instituições podem ser estudadas a partir de duas vertentes analíticas. A primeira, de natureza 
macrodesenvolvimentista, focaliza a origem, estruturação e mudanças das instituições. A segunda, de natureza microinstitucional, preocupa-se com a análise de estruturas de governança, o que pode ser feito a partir da ECT. Apresentando a transação como unidade de análise, a ECT tem como objetivo controlar os direitos de propriedade por meio do alinhamento entre as estruturas de governanças (mercado, hierarquia e contratos), atributos de transação (especificidade de ativos, frequência e incerteza) e pressupostos comportamentais (oportunismo e racionalidade limitada).

$\mathrm{Na}$ estrutura de governança via mercado, conforme Williamson $(1985,1996)$, o nível de especificidade de ativos é baixo; logo, os custos de transação são mínimos. Os agentes conhecem as características dos produtos transacionados, a incerteza e a frequência nas transações não são relevantes e, normalmente, não se cria reputação entre as partes. Já a integração vertical ou hierarquia, conforme o autor, é motivada pela possibilidade de comportamento oportunista, tendo em vista um alto nível de frequência, de incerteza e, principalmente, de especificidade de ativos (locacional, temporal, humana, de marca, física e dedicada).

Já os contratos ou formas híbridas, de acordo com Ménard (2004), referem-se aos arranjos de coordenação das transações que se diferem das estruturas via mercado e integração vertical.
Eles podem se fazer necessários para garantir que não haja captura da quase renda pelas partes envolvidas, ou seja, para garantir que não ocorra a perda ou expropriação do valor econômico do produto ou serviço transacionado. Segundo Ménard (2004), na medida em que as partes vão se conhecendo, aumenta o uso de mecanismos informais, tais como reputação, confiança, compartilhamento de informações e ajuda mútua, que são utilizados na coerção dos agentes. Na Figura 1, o autor segmenta as formas híbridas em confiança, rede relacional, liderança e governança formal, as duas primeiras próximas da estrutura via mercado e as duas últimas, da estrutura hierárquica.

Outra questão que deve ser observada são os diferentes níveis de incentivo e de controle que a firma dispõe para organizar suas atividades, discutidos por Williamson (1985) e posteriormente tratados por Mizumoto e Zylbersztajn (2006). Segundo os autores,

arranjos via mercado são os que oferecem mais incentivos, mas a possibilidade de controle depende da existência de parceiros substitutos para disciplinar os desvios em relação ao acordo (p. 150).

Sendo assim, conforme aumenta a necessidade de controle, a firma passa a optar por arranjos

Figura 1. Estruturas de governança.

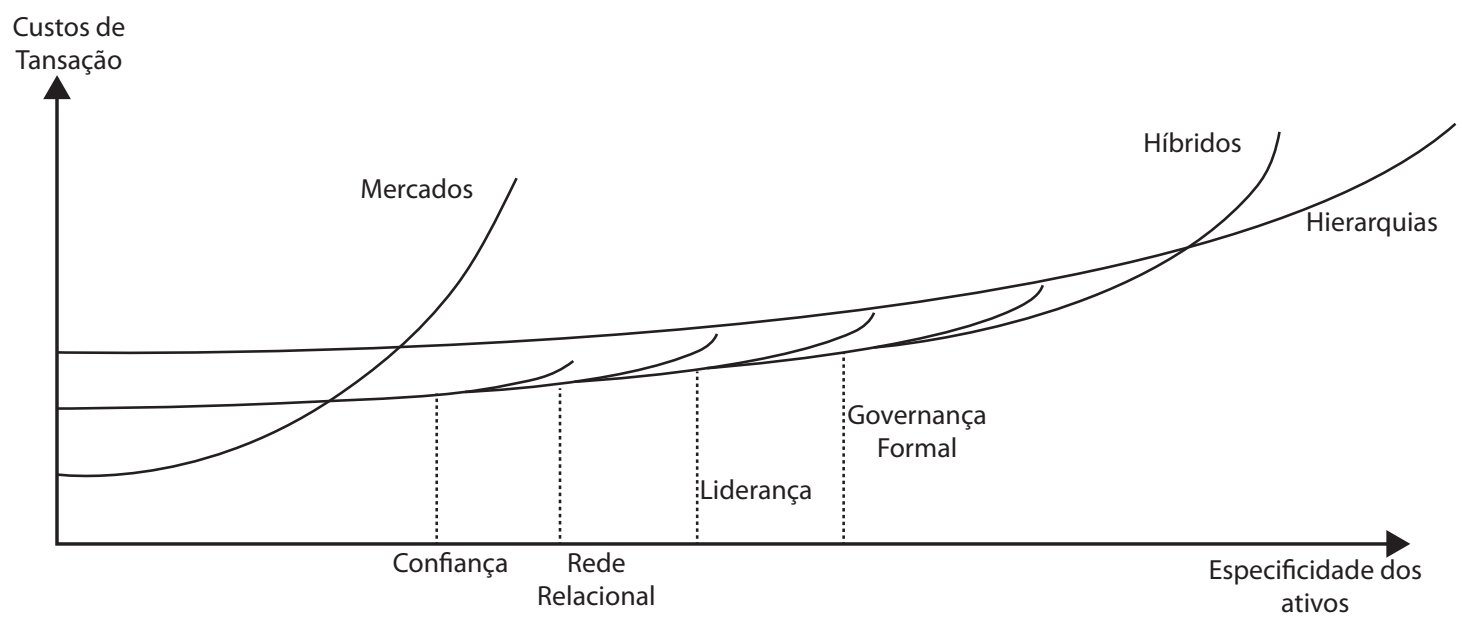

Fonte: Ménard (2002, p. 22). 
contratuais em que é possível utilizar a ameaça de litígio para fazer cumprir o contrato. Nesse caso, a firma opta por arranjos hierarquizados em que as atividades são coordenadas internamente, ao preço de um incentivo menor, vis à vis ao arranjo via mercado.

\subsection{Visão baseada em recursos}

Segundo Mintzberg et al. (2000), a Visão Baseada em Recursos (do inglês, Resource Based View - VBR) tem sua origem na teoria econômica, especialmente a partir dos estudos de Penrose (1959), que defendeu que as empresas desenvolvem suas vantagens competitivas por meio das imperfeições do mercado. Essas imperfeições apresentam singularidades que geram a base para o desenvolvimento de novos produtos e, simultaneamente, de capacidades e recursos únicos, aqui denominados de recursos estratégicos.

Mintzberg (2000) observa que, apesar da constatação de Penrose (1959), esses ativos só passam a ser considerados de forma efetiva a partir do trabalho de Wernefelt (1984), em que é estabelecido um paralelo entre a visão tradicional baseada em produtos, defendida pelo modelo competitivo de Porter (1985), e a visão baseada em recursos. Para o autor, as ideias de Wernefelt só avançaram a partir de 1990, quando Prahalad e Hamel popularizaram sua visão a respeito de capacidades dinâmicas.

Barney (1991) complementa a perspectiva original de Penrose (1959), afirmando que o conjunto de recursos da firma não é somente uma lista de fatores, mas o processo de interação entre esses recursos. Na visão de Barney (1991), para serem estratégicos, os recursos devem ser valiosos, raros, imperfeitamente imitáveis e insubstituíveis, de modo a possibilitar que a empresa alcance estratégias eficazes. Eles podem ser classificados como recursos de capital físico (tecnologia, fábrica, equipamentos, localização geográfica, acesso a matérias-primas), de capital humano (treinamento, experiência, inteligência, relacionamentos) e de capital organizacional (sistemas e estruturas formais, bem como relações informais entre grupos).
Após Barney (1991), Peteraf examina as condições dos recursos que asseguram as vantagens competitivas sustentáveis, em seu artigo The cornerstones of competitive advantage, publicado em 1993. Na visão da autora, os recursos rendem uma vantagem competitiva sustentável para a empresa quando apresentam: superioridade, no sentido de serem heterogêneos, para garantir a obtenção de lucros diferenciais; barreiras ex post à competição, ou seja, serem difíceis de imitar devido a mecanismos de isolamento presentes; barreiras ex-ante à competição, em que assimetrias de informação são necessárias para limitar a competição explícita pelos recursos; imobilidade, quando possuírem especialização ou especificidade que os tornam adaptados exclusivamente para suas necessidades.

Nesse contexto, as rendas diferenciais fluem de ativos específicos da firma, que não podem ser imediatamente replicados, recebendo a denominação de rendas ricardianas. Segundo Saes (2009), o conceito de rendas ricardianas deriva do trabalho de David Ricardo intitulado On the principles of political economy and taxation, de 1921. Ao analisar a produção agrícola, Ricardo observou que o preço do produto agrícola seria determinado pela oferta de terra e de sua fertilidade. Nesse aspecto, quanto maior a fertilidade, maior a renda para o produtor que possui a terra fértil. Portanto, essas rendas são devidas a fatores valorizados, mas inerentemente raros e difíceis de serem obtidos.

Nota-se que diversos estudiosos têm focado seu trabalho na descrição dos recursos e capacidades estratégicos inerentes ao ambiente interno das organizações. Ainda que diversos progressos tenham sido alcançados, desde os pensadores clássicos como Penrose (1959), Wernerfelt (1984), Barney (1991) e Peteraf (1993), com seu foco nas relações intraorganizacionais, evidencia-se a necessidade de continuidade dos estudos na área.

\subsection{Especificidades: ECT E VBR}

Nos últimos anos, uma convergência entre a ECT e a VBR foi iniciada, buscando uma explicação mais satisfatória para os limites da firma. 
Para Jacobides e Winter (2005), economistas dos custos de transação agora aceitam que não se pode compreender inteiramente as escolhas de fronteiras sem avaliar as bases de recursos das empresas.

Argyres e Zenger (2008) consideram que a lógica baseada em recursos tem sido estendida para além das explicações do desempenho das firmas para explicações sobre a sua configuração e os seus limites. $\mathrm{O}$ argumento proposto para explicar estes limites é bastante simples: "as empresas governam internamente capacidades comparativas e terceirizam o acesso às capacidades onde a firma é comparativamente incompetente" (p. 6). A partir desta lógica, percebe-se que as capacidades que a empresa possui também determinam os seus limites, uma vez que as decisões de fazer ou comprar são tomadas levando-se em conta a sua existência.

Na visão de Poppo e Zenger (1997), as escolhas dos limites surgem como decisões de importância estratégica primária, uma vez que, se a vantagem competitiva deriva de recursos valiosos e difíceis de imitar, pela VBR, então, essas escolhas definem a posse e composição de tais recursos. Por sua vez, a ECT é vista como uma teoria que explica a gestão eficiente do desenvolvimento de uma capacidade única ou específica da firma (ARGYRES e ZENGER, 2008). Em consonância a esse argumento, Langlois (1992) afirma que "em conjunto com os custos de governança, as capacidades da empresa e do mercado determinam os limites da firma no curto prazo" (p. 99). Isto porque o autor defende a existência de custos de governança dinâmicos, que se referem a custos de informação ou conhecimento relacionados à transferência de capacidades das empresas para o mercado, ou vice-versa.

Sendo assim, as considerações da VBR caminham lado a lado com as considerações da ECT. Argyres e Zenger (2008) defendem que as considerações sobre as capacidades e os custos de transação são tão interligadas que deveriam ser integradas como parte de uma única teoria dos limites da firma. Visto nessa perspectiva, a explicação para a escolha das fronteiras da empresa que se baseie inteiramente, ou em grande parte, em considerações de uma das abordagens não pode fornecer explicação suficiente para uma decisão de fazer ou comprar. Essa complementaridade é aprofundada na seção a seguir.

\subsubsection{Aspectos complementares: ECT e VBR}

Apesar de os estudiosos da VBR introduzirem uma lógica nova para explicar as virtudes da governança da empresa, os argumentos são muito consistentes com as linhas conceituais amplas da ECT. Na percepção de Agyres e Zenger (2008), enquanto a ECT define as virtudes da hierarquia na superação das falhas de mercado, os estudiosos da VBR articulam mais plenamente sobre as virtudes da hierarquia na geração de capacidade. Ou seja, a VBR afirma que a razão pela qual uma atividade é realizada dentro da empresa não é somente a falha do mercado ou custos de transações que podem ocorrer, mas, sim, o sucesso da empresa.

Seguindo esse raciocínio, Poppo e Zenger (1997) defendem que a integração vertical pode ocorrer não apenas pela presença de ativos específicos ou comportamento oportunista, mas pelo fato de a organização, por si mesma, apresentar características vantajosas como opção de governança. Para Ghoshal e Moran (1996), as vantagens das organizações sobre os mercados podem explorar os propósitos internos da organização para "[...] alavancar a habilidade humana para tomar a iniciativa, para cooperar e para aprender" (p. 42).

Langlois (1992) defende que "[...] não se pode ter uma teoria completa das fronteiras da empresa sem considerar em detalhe o processo de aprendizado em empresas e mercados" (p. 105). Este argumento também está entrelaçado com a constatação de Argyres e Zenger (2008) de que a distribuição dos recursos nas empresas, em um determinado momento, reflete uma série de decisões passadas que estas empresas tomaram para desenvolver ou não desenvolver capacidades internamente. Segundo os autores, essas decisões foram possivelmente impulsionadas pela comparação da eficiência dos tipos de governança ou por considerações de custo de transação advindas de um processo de aprendizagem. 
Na mesma linha de pensamento, Saes (2009) afirma que a VBR suporta a escolha de estruturas de governança, uma vez que as mudanças nessas estruturas dependem de um processo de realimentação, a partir do aprendizado e experiências pessoais dos gerentes sobre os custos de transação envolvidos. Por outro lado, a ECT explica quais estruturas de governança são mais eficientes para explorar os recursos estratégicos da firma (WILLIAMSON, 2002; JACOBIDES e WINTER, 2005).

$\mathrm{Na}$ visão de Argyres e Zenger (2008), a VBR trata de como lidar com a questão de quais recursos complementam-se para produzir uma vantagem competitiva, enquanto a ECT lida com a questão de quais desses recursos complementares ficará sob propriedade comum da empresa e quais serão de propriedade independente. Sendo assim, enquanto a VBR busca a identificação de recursos estratégicos que exigem melhorias, a ECT incide sobre a forma de gerir esses recursos depois de identificados (COMBS e KETCHEN, 1999).

Outro ponto de complementaridade está relacionado à especificidade de ativos. Isso porque os recursos estratégicos da firma (VBR) podem ser interpretados como ativos específicos e, assim, analisados a partir do instrumental da ECT. Combs e Ketchen (1999) ressaltam que a visão das abordagens é complementar, em parte, devido ao reconhecimento de que ativos específicos compartilham uma qualidade importante com os recursos estratégicos, ou seja, ambos são difíceis de comercializar ou imitar. Segundo os autores, essa complementaridade esclarece porque o alto desempenho entre as empresas pode ser explicado tanto como um produto da gestão organizacional focada na eficiência (ECT), quanto da exploração de recursos estratégicos (VBR).

Nota-se, ainda, que o controle assume papel fundamental nas duas teorias. Pelo lado da VBR, é necessário que recursos e capacidades diferenciadas sejam controlados para manterem sua condição de não mobilidade. Já pelo lado da ECT, o controle se relaciona mais a minimização de condição de incerteza. Neste sentido, Zylbersztajn (2009) observa que, com relação à incerteza [...], inesperados choques externos [...] podem ter consequências reais imprevistas. Portanto, a incerteza motiva a necessidade de um controle mais intenso (p. 9).

Desse modo, o controle mesmo direcionado à redução de mobilidade de recursos permite que as respostas em condições de incerteza sejam mais rápidas, denotando que tanto a VBR quanto a ECT adotam o controle como justificativa para suas abordagens.

Sendo assim, pela VBR, o controle torna-se aspecto fundamental quando se considera a proteção de recursos, o que pode se dar na existência dos custos de transação. Como destaca Saes (2009), a importância dos custos de transação é que, na sua ausência, não haveria o problema de criação e proteção de valor dos recursos, sendo que qualquer estrutura de governança seria apropriada e conduziria à maximização do valor. No entanto, a autora afirma que, quando os custos de transação são introduzidos, os direitos de propriedade dos recursos não são perfeitamente protegidos e seus valores podem ser dissipados.

Desse modo, é possível afirmar que a obtenção de recursos estratégicos pode caracterizar direito de propriedade que necessita ser protegido por mecanismos legais ou estruturais. Com isso, quanto mais efetivo for o controle, maior será a proteção dos direitos de propriedade e menos custosas serão as atividades realizadas para a sustentação de valor do recurso. O Quadro 1 sintetiza os pontos de convergência na consideração das duas teorias como orientação para geração de capacidade competitiva e explicação para os limites da firma.

Um último ponto destacado no Quadro 1 é que as diferentes limitações cognitivas e especificidades de ativos existentes entre as empresas, temas discutidos pela ECT, também explicam a heterogeneidade das firmas tratada pela VBR (SAES, 2009). Conforme Foss e Foss (2004), o conceito de heterogeneidade ainda pode ser abordado pela ECT a partir da consideração de como se dão os direitos de propriedade entre as firmas. 
Quadro 1. Pontos de convergência entre a ECT e a VBR.

\begin{tabular}{|c|c|c|}
\hline ECT & VBR & Pontos de Convergência entre a ECT e VBR \\
\hline $\begin{array}{l}\text { Discute virtudes da hierarquia como } \\
\text { superação das falhas de mercado. }\end{array}$ & \begin{tabular}{|l|} 
Discute virtudes da hierarquia na \\
geração de capacidade para a empresa.
\end{tabular} & Ambas discutem as virtudes da hierarquia. \\
\hline \begin{tabular}{l|} 
As decisões tomadas pela empresa \\
são impulsionadas pela comparação \\
da eficiência dos tipos de governança \\
possíveis ou por considerações de \\
custos de transação.
\end{tabular} & $\begin{array}{l}\text { A distribuição dos recursos nas firmas } \\
\text { em um determinado momento reflete } \\
\text { uma série de decisões passadas. }\end{array}$ & $\begin{array}{l}\text { O processo de aprendizagem da empresa } \\
\text { no passado determina a distribuição de } \\
\text { recursos e as estruturas de governanças } \\
\text { utilizadas pela empresa no presente. }\end{array}$ \\
\hline $\begin{array}{l}\text { Identifica quais estruturas } \\
\text { de governança reduzirão os custos } \\
\text { de transação. }\end{array}$ & $\begin{array}{l}\text { Identifica quais recursos trazem } \\
\text { vantagem competitiva }\end{array}$ & $\begin{array}{l}\text { Identifica quais estruturas de governança são } \\
\text { mais eficientes para explorar os recursos } \\
\text { estratégicos da firma. Por outro lado, recursos } \\
\text { e capacidades também suportam a escolha de } \\
\text { estruturas de governança adequadas. }\end{array}$ \\
\hline Ativos específicos. & Recursos e capacidades estratégicos. & Ambos são difíceis de comercializar e imitar. \\
\hline $\begin{array}{l}\text { O controle se relaciona mais à mini- } \\
\text { mização de condição de incerteza, } \\
\text { uma vez que fortalece garantias de } \\
\text { direito de propriedade. }\end{array}$ & $\begin{array}{l}\text { O controle se dá sobre recursos e } \\
\text { capacidades diferenciadas com o } \\
\text { objetivo de manterem sua condição } \\
\text { de não mobilidade. }\end{array}$ & $\begin{array}{l}\text { O controle, mesmo direcionado à redução de } \\
\text { mobilidade de recursos, permite que as respostas } \\
\text { em condições de incerteza sejam mais rápidas. }\end{array}$ \\
\hline $\begin{array}{l}\text { A necessidade de proteger os } \\
\text { direitos de propriedade } \\
\text { demanda custos de transação. }\end{array}$ & $\begin{array}{l}\text { Recursos e capacidades } \\
\text { estratégicos criam valor e devem } \\
\text { ser protegidos, o que pode ocorrer } \\
\text { através da integração vertical. } \\
\end{array}$ & $\begin{array}{l}\text { A construção de recursos e capacidades } \\
\text { pode caracterizar direito de propriedade } \\
\text { que necessita ser protegido por mecanismos } \\
\text { legais ou estruturais. }\end{array}$ \\
\hline $\begin{array}{l}\text { Racionalidade limitada; } \\
\text { especificidade de ativos; } \\
\text { direitos de propriedade. }\end{array}$ & Heterogeneidade de recursos. & $\begin{array}{l}\text { Diferentes recursos sujeitos à racionalidade } \\
\text { limitada, especificidades de ativos e direitos de } \\
\text { propriedade entre as firmas também as tornam } \\
\text { heterogêneas. }\end{array}$ \\
\hline
\end{tabular}

Isso porque, para o autor, as diferenças entre elas se dão a partir da forma particular em que cada uma aloca internamente os direitos de propriedades de seus recursos. Assim, o valor que o proprietário de um recurso pode criar vai depender do conjunto de direitos de propriedade que ele possui em sua firma, que pode diferir das demais.

\section{Metodologia}

Para desenvolver o objetivo proposto neste trabalho, adotou-se a pesquisa de natureza qualitativa do tipo descritiva, sendo os dados coletados por intermédio de entrevistas semiestruturadas. O recorte utilizado foi o transversal, com perspectiva longitudinal, ou seja, as informações foram coletadas em um ponto no tempo, para descrever o fenômeno em um determinado momento (transversal), mas incluem uma noção de mudança ao longo de um dado período (perspectiva longitudinal).
A análise e interpretação dos dados obtidos foram feitas por intermédio do método de análise de conteúdo. Bardin (2004) assinala três etapas básicas de um trabalho que usa este método, as quais foram utilizadas na realização do presente estudo:

1. Pré-análise: foram definidos o tema, o referencial teórico, os objetivos e a metodologia, e foram realizadas a coleta dos dados primários e secundários e a transcrição das entrevistas;

2. Análise descritiva: organização e descrição dos dados coletados, envolvendo a codificação por meio da classificação (intensidade e direção de ideias) e categorização (definição de categorias a serem trabalhadas (Figura 1);

3. Interpretação inferencial: compreensão dos fenômenos a partir dos materiais teóricos e empíricos, busca de respostas às questões de pesquisa levantadas, verificação de contradições e, por fim, realização das conclusões. 
Destaca-se que, na análise de conteúdo realizada na presente investigação, a escolha das categorias se deu pelo referencial teórico e pelos objetivos apresentados. Portanto, tem-se como pressuposto que os custos de transação, em conjunto com os recursos estratégicos da empresa, podem configurar as estruturas de governança que, por sua vez, afetam a capacidade de resposta ao aparato legal ambiental nas relações entre produtores e processadores do setor alcooleiro paranaense. Esse raciocínio estabelece as categorias de estudo que são apresentadas na Figura 2.

Para o trabalho empírico foram selecionadas apenas as destilarias fabricantes de etanol, envolvendo sete unidades, presentes no Paraná. A escolha pelas destilarias se deu como forma de focar indústrias que possuem o mesmo porte, realizam o mesmo processo produtivo e tendem a se utilizar de recursos similares.

Para investigar as destilarias, foram coletados dados primários e secundários. Os dados secundários foram buscados em organizações como a Associação de Produtores de Bioenergia do Estado do Paraná (Alcopar), União da Indústria de Cana-de-Açúcar (Unica) e Instituto Ambiental do Paraná (IAP). No que diz respeito aos dados primários, eles foram coletados por meio de entrevistas semiestruturadas realizadas com gerentes agrícolas e com fornecedores de cana mais antigos das destilarias pesquisadas.

Como tanto a ECT (frequência) quanto a VBR (path dependencies) indicam o fator tempo como um elemento que define a maneira como as transações se configuram, foram selecionadas as destilarias e fornecedores contratados que estão na atividade há pelo menos dez anos. Dessa forma, dentre as sete destilarias existentes no estado, cinco atenderam à solicitação de entrevista, pois uma não é aberta a pesquisas e outra não atendia o critério estabelecido, relacionado ao tempo na atividade. $\mathrm{O}$ perfil das cinco destilarias selecionadas encontra-se no Quadro 2. A referência dos fornecedores ouvidos (um para cada destilaria) foi obtida nas próprias destilarias, na fase de realização das entrevistas. Essas entrevistas com produtores foram direcionadas à realização de triangulação para obtenção de validade interna e maior confiabilidade nos dados fornecidos pelos gerentes agrícolas.

Figura 2. Esquema de análise - categorias de estudo.
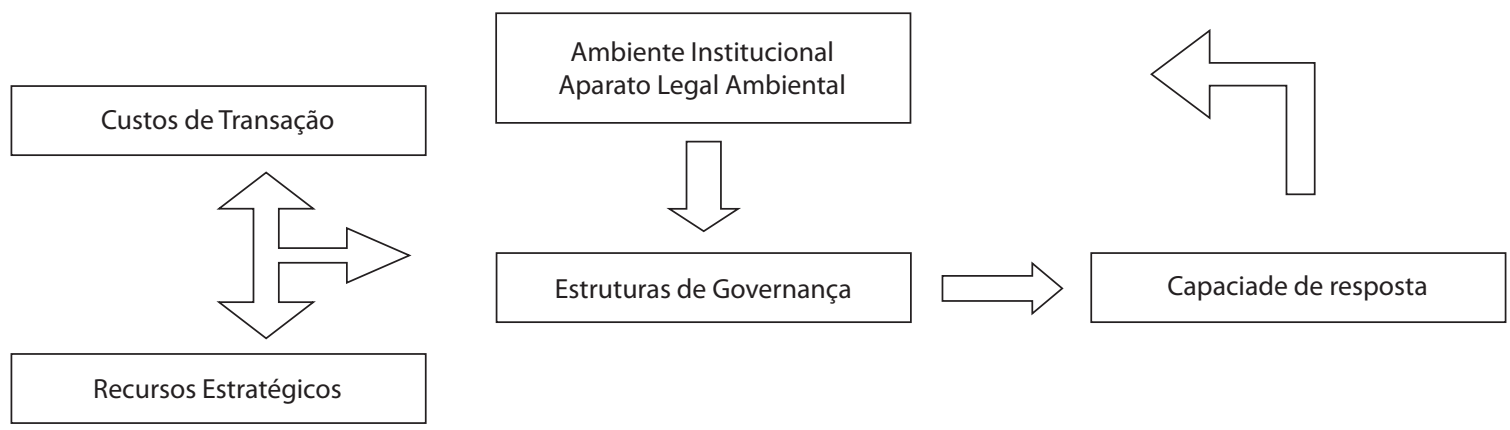

Quadro 2. Amostra das destilarias localizadas no estado do Paraná por tempo de atuação.

\begin{tabular}{|c|c|c|c|c|}
\hline Destilarias & Mesorregião & Ano de fundação & Tempo de atuação & Produtos \\
\hline A & Norte Central & 1999 & 11 anos & Álcool \\
\hline B & Noroeste & 1981 & 29 anos & Álcool \\
\hline C & Norte Pioneiro & 1986 & 24 anos & Álcool \\
\hline D & Noroeste & 1962 & 48 anos & Álcool \\
\hline E & Norte Pioneiro & 1976 & 34 anos & Álcool \\
\hline
\end{tabular}




\section{Apresentação e discussão dos resultados}

\subsection{Leis ambientais}

A partir das entrevistas realizadas identificou-se que a questão ambiental, que interfere na relação da destilaria com os seus contratados, resume-se ao atendimento do Código Florestal. Estabelecido a partir da Lei n. 4.771 de 15 de setembro de 1965, o Código Florestal é apontado como a mais importante lei que regula as atividades ambientais nas destilarias paranaenses. Nela, são discutidas as condições quanto à instituição de áreas de preservação permanente e áreas de reserva legal e quanto à prática de queimadas.

As áreas de reserva legal equivalem a $20 \%$ da propriedade que deve ser recomposta com vegetação. As reservas permanentes, por sua vez, referem-se à formação vegetal localizada nas margens dos rios, córregos, lagos, represas e nascentes. A partir do Código Florestal (1965), as medições da mata ciliar de nascentes, córregos, riachos e rios são realizadas, tendo como base os limites estabelecidos no Art. $2^{\circ}$, onde as metragens das áreas são deixadas de acordo com a largura dos corpos hídricos (CÓDIGO FLORESTAL, 1965). No tocante às queimadas, ainda não existe uma legislação específica para sua regulação no estado do Paraná, sendo que a sua prática depende de liberações realizadas anualmente pelo IAP, a partir de garantias de controle e uso criterioso por parte das destilarias (IAP, 2010).

Todos os entrevistados asseguram, de forma unânime, que as leis ambientais são impostas, e cabe às destilarias somente se adequar para que não prejudique o seu funcionamento, uma vez que existem órgãos ambientais com autoridade que fiscalizam e acompanham o seu cumprimento. Como essas leis são praticadas nas relações que as destilarias têm com seus contratados, elas influenciam a dinâmica operacional das atividades na área agrícola. Percebeu-se que essa influência se dá tanto nas atividades realizadas no plantio quanto na colheita.

Sobre os procedimentos relacionados ao plantio, as reservas permanentes e legais são as que mais afetam a condição operacional na relação das destilarias com produtores, devido à redução da área plantada e, consequentemente, da capacidade produtiva. Outra característica que influencia a dinâmica operacional, conforme apontado pelos entrevistados, diz respeito à responsabilidade de averbação das reservas. Quando a destilaria é a proprietária da terra, ela mesma se encarrega de averbar suas reservar legais e permanentes. No caso dos contratos, essa averbação se estabelece como condição para os fornecedores conseguirem realizar transações com a destilaria.

Quanto aos procedimentos relacionados à colheita, o principal fator que estabelece condições operacionais nas atividades das destilarias e produtores pesquisados refere-se à sua mecanização. Isso porque, diante de uma tendência nacional para extinguir as queimadas, uma das opções que surge para que isso aconteça é a automatização da colheita. Além de aumentar a produtividade agrícola, as queimadas ocorrem para evitar que animais peçonhentos possam picar os cortadores de cana. Nesse caso, como a mecanização elimina a colheita manual, as queimadas não são necessárias. A participação da colheita mecanizada na colheita das destilarias paranaenses, de acordo com os gerentes agrícolas entrevistados, pode ser visualizada na Tabela 1 . Nota-se que apenas a Destilaria D ainda não está seguindo a tendência legal para extinção das queimadas, mas já apresenta planos para o inicio da mecanização para o próximo ano.

Tabela 1. Porcentagem de colheita mecanizada nas destilarias paranaenses.

\begin{tabular}{rccccc}
\hline Destilarias & Destilaria A & Destilaria B & Destilaria C & Destilaria D & Destilaria E \\
\hline Colheita mecanizada & $60 \%$ & $72 \%$ & $35 \%$ & $0 \%$ & $40 \%$ \\
\hline
\end{tabular}


Percebe-se, então, que a quase totalidade das destilarias investigadas, em maior ou menor grau, estão se adequando às tendências legais relacionadas à extinção das queimadas, adotando, para isso, a mecanização da colheita. No entanto, é válido destacar que, para realizar a mecanização, é necessário que os terrenos sejam adequados ao recebimento da máquina, sendo que nem todas as terras contratadas apresentam tal característica topográfica. O principal aspecto que influencia a dinâmica operacional das destilarias e altera as estruturas de governança, nesse sentido, é a priorização de proprietários que apresentem terrenos mais planos, favoráveis à entrada de máquinas colheitadeiras.

No caso das atividades de plantio, as destilarias que praticam integração vertical (terra própria) e contratos de parceria do tipo arrendamento (cana própria) são responsáveis pela ocorrência da quaisquer tipos de problemas ambientais. Já no caso do contrato de parceria agrícola, essa responsabilidade é dividida entre a destilaria e o produtor, sendo que, no contrato de fornecimento, a responsabilidade fica por conta do proprietário da terra. Nas atividades de colheita, como as destilarias normalmente realizam o CCT, elas se tornam responsáveis diante da ocorrência de quaisquer tipos de problemas, independente do tipo de contrato firmado. Nesse aspecto, o principal problema apontado pela grande maioria dos gerentes entrevistados refere-se à queima acidental de áreas de reserva permanente ou legal. As questões operacionais geradas a partir da aplicação das principais exigências ambientais listadas pelas destilarias e produtores podem ser sintetizadas no Quadro 3.

As afirmações acima corroboram o controle advindo das instituições, apresentado por
Williamson (1996), cujas regras regulam a configuração das estruturas de governança utilizadas nas transações entre os agentes. Isso porque, enquanto as reservas impactam na área útil, nos custos e no volume da produção, e na renda das partes envolvidas, uma vez que elas deixarão de receber pela plantação nas áreas protegidas, as queimadas trazem como exigência a mecanização e, consequentemente, a escolha, por parte das destilarias, de proprietários que possuam terrenos adequados.

Portanto, essas especificidades legais vêm afetar diretamente a relação da destilaria com seus contratados, uma vez que novas exigências relacionadas ao tipo de terreno são feitas, postos de trabalho relacionados ao corte de cana são extintos e, ao mesmo tempo, novos postos são criados, alterando as condições de trabalho e a dinâmica operacional das destilarias investigadas. Diante disso, as indicações de Douglas North (1991), que parte do pressuposto de que as instituições são as regras do jogo e as organizações são os jogadores, cuja arquitetura é pautada pelo ambiente institucional, também são confirmadas.

A partir da classificação de Zylbersztajn (2009), percebe-se que as leis ambientais são tratadas sob um ponto de vista macroanalítico, definindo parâmetros legais para as interações das agroindústrias e destilarias no setor. Já o segundo nível de análise trata das microinstituições que regulam transações específicas e se constituem por meio de estruturas de governança. Nesse sentido, o próximo tópico se dedica à identificação dos tipos de estruturas de governança adotadas e, ainda, à descrição de como essas estruturas definem condições operacionais específicas às atividades das destilarias e dos produtores estudados. 


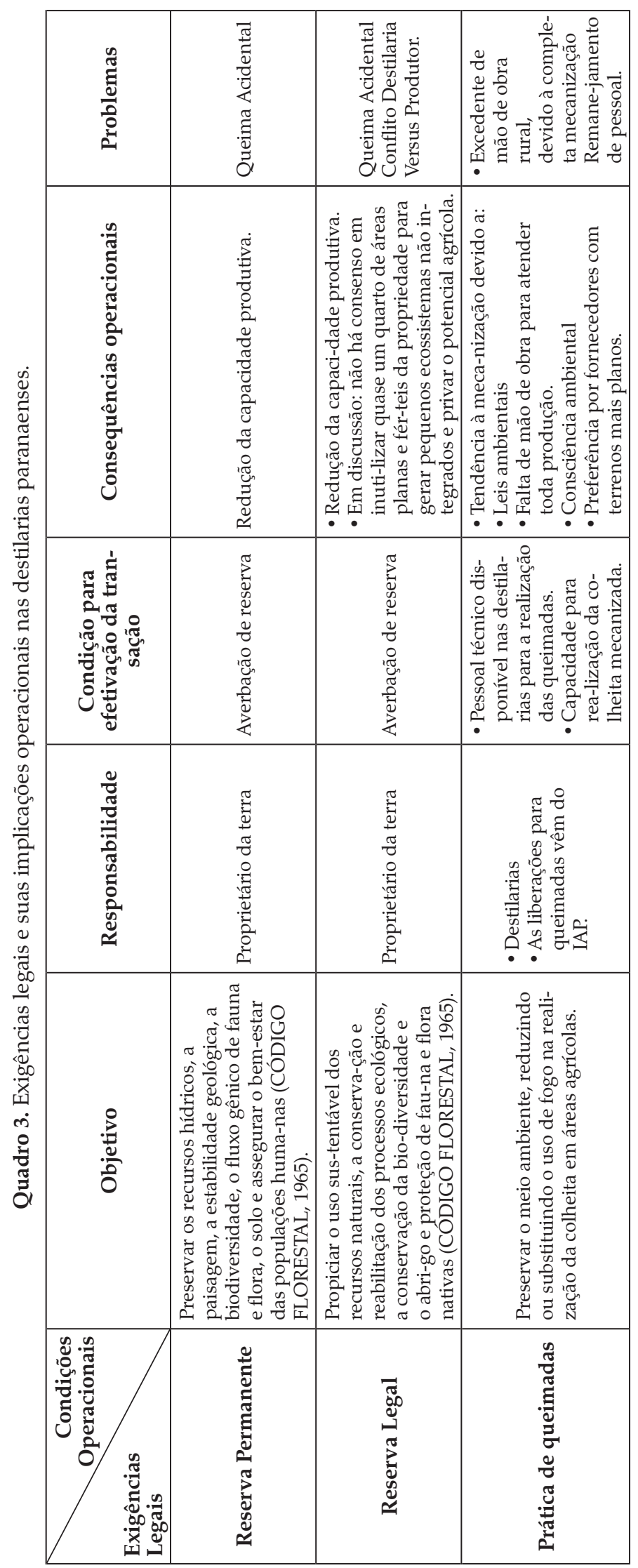

RESR, Piracicaba-SP, Vol. 50, № 3, p. 411-434, Jul/Set - Impressa em Setembro de 2012 


\subsection{Estruturas de governança no setor alcooleiro}

A frequência nas transações, caracterizada pela necessidade contínua por parte das destilarias de adquirir a matéria-prima cana, a possibilidade de comportamento oportunista, bem como a especificidade locacional e temporal, principalmente, justificam as estruturas contratuais, tendendo à integração vertical (WILLIAMSON, 1985), como predominantes nas destilarias pesquisadas. Conforme a Tabela 2, que indica a participação das estruturas de governança na aquisição de cana-de-açúcar pelas destilarias paranaenses, é possível perceber que, em sua grande maioria, estas estruturas se dão por meio de contrato de parceria do tipo arrendamento.

Como segunda opção de arranjo organizacional identifica-se o contrato de parceria agrícola, seguido pelo contrato de fornecimento. O mercado e a integração vertical são arranjos pouco utilizados normalmente, devido à imprevisibilidade presente e à necessidade de alto investimento em terras, respectivamente. A exceção fica por conta da destilaria $B$, cuja posse prévia de terras resultou na prática da integração vertical, realizando contratos apenas para atender à necessidade de expansão da produção.

Ao se considerar essas estruturas, é válido notar que, quanto à integração vertical, os gerentes agrícolas das destilarias que utilizam esse tipo de arranjo afirmam que só o adotam pelo fato de os donos das destilarias possuírem a posse prévia de terras. Para os entrevistados, a principal van- tagem da integração vertical é o controle obtido, tanto da terra quanto do processo produtivo da cana, considerada um ativo específico físico. Desse modo, não existe possibilidade de conflitos, ratificando-se os pressupostos de Williamson (1985) quanto aos benefícios dessa forma de governança na presença de ativos específicos.

Quanto ao contrato de parceria do tipo arrendamento, o principal argumento demonstrado nas entrevistas é que esse tipo de contrato possibilita às destilarias obterem maior controle, sem precisarem investir na aquisição de terras. Esse controle influencia a dinâmica operacional das destilarias, sendo desejado para efeito de programação, uma vez que aumenta a autonomia em caso de incertezas, a um custo menor que a integração vertical.

Essa constatação é corroborada por Williamson (1985), Mizumoto e Zylbersztajn (2006), no que refere aos diferentes níveis de incentivo e controle que a organização pode ter na escolha de um arranjo organizacional. Para os autores, conforme a necessidade de controle aumenta, a empresa passa a optar por arranjos contratuais hierarquizados em que as atividades são coordenadas internamente, ao preço de um incentivo menor em comparação ao arranjo via mercado.

No caso de medidas de expansão, os entrevistados são unânimes ao argumentar que, caso a destilaria queira manter o controle, são priorizadas as relações contratuais via parceria do tipo arrendamento, que não necessitam de grandes quantias imobilizadas. Embora não sejam verificadas práticas de hold-up e de comportamentos

Tabela 2. Estruturas de governança adotadas pelas destilarias paranaenses.

\begin{tabular}{|c|c|c|c|c|c|c|}
\hline $\begin{array}{l}\text { Destilaria/ } \\
\text { Estrutura }\end{array}$ & $\begin{array}{l}\text { Quantidade de } \\
\text { terras/hectares }\end{array}$ & $\begin{array}{c}\text { Integração } \\
\text { vertical }\end{array}$ & $\begin{array}{l}\text { Contrato de } \\
\text { parceria do tipo } \\
\text { arrendamento }\end{array}$ & $\begin{array}{l}\text { Contrato } \\
\text { de parceria } \\
\text { agrícola }\end{array}$ & $\begin{array}{l}\text { Contrato de } \\
\text { fornecimento, } \\
\text { com CCT }\end{array}$ & Mercado \\
\hline Destilaria A & 5.996 há & & $100 \%$ & & & \\
\hline Destilaria B & 21.000 há & $90 \%$ & & $5 \%$ & $5 \%$ & \\
\hline Destilaria C & 7.483 há & $10 \%$ & $45 \%$ & $45 \%$ & & $10 \%$ \\
\hline Destilaria D & 11.400 há & $10 \%$ & $45 \%$ & $45 \%$ & & \\
\hline Destilaria E & 14.000 há & $35 \%$ & $35 \%$ & & $30 \%$ & \\
\hline
\end{tabular}


oportunistas expressivos, essa possibilidade existe devido à presença de ativos específicos, justificando o uso de contratos de arrendamento como alternativa à integração vertical, dado que oferecem as mesmas vantagens. Esses fatores ratificam as proposições de Coase (1937) e Williamson (1985) presentes na literatura quanto aos motivos da utilização de estruturas mais integradas.

Quanto ao contrato de parceria agrícola e de fornecimento, os entrevistados apontam que as principais vantagens são o aumento da capacidade produtiva, a divisão de responsabilidades e o compartilhamento das incertezas associadas à produção. Ao contrário do contrato de parceria do tipo arrendamento, o contrato de parceria agrícola permite ao produtor compartilhar os benefícios do mercado relacionados ao acréscimo dos preços e ao crescimento do setor.

Conforme os entrevistados, os contratos de parceria agrícola e fornecimento são os que mais influenciam as condições operacionais das destilarias, devido à interdependência que ocorre entre as partes. Sendo assim, eles podem afetar a dinâmica das destilarias à medida que o abastecimento do processo industrial depende da cana de terceiros. Outra condição operacional impactada por esses contratos refere-se à produtividade agrícola no cultivo de cana-de-açúcar. Segundo os gerentes agrícolas, há possibilidade de se conseguir uma produtividade maior quando o produtor ou proprietário participa ou gerencia o processo produtivo, pelos cuidados mais apurados que ele tem com a terra. Por outro lado, o contrário também pode acontecer, ou seja, os proprietários deixam de investir na propriedade, devido à queda nos preços ou a uma situação desfavorável no mercado da cana-de-açúcar.

Os entrevistados alegam que atitudes desse tipo, no sentido de prejudicar a produtividade do plantio, ocorrem menos quando se conhece o proprietário e se estabelece uma relação de confiança com ele. Nesse aspecto, é corroborado o ponto destacado por Ménard (2002) de que o uso de mecanismos informais, como a confiança, por exemplo, serve como um mecanismo de coerção sobre as partes, contribuindo para evitar comportamentos oportunistas, o que se constatou nas destilarias pesquisadas.

Quanto ao mercado livre, os entrevistados afirmam que esta prática não é comum. Isso porque a cana, como principal matéria-prima das destilarias, demanda custos de transação pela sua alta especificidade física, descartando o mercado pela incerteza presente nesse tipo de transação. Esse argumento vem ao encontro da afirmação de Williamson (1985), que aponta que a estrutura de governança via mercado mostra-se mais eficiente quando ativos de baixa especificidade estão envolvidos na transação, o que não é o caso da cana-de-açúcar. Ao se considerar a VBR, observa-se que recursos estratégicos não estão disponíveis no mercado, e como a cana e o controle sobre o seu processo produtivo configuram recurso estratégico, isso explicaria a pouca utilização dessa estrutura de governança.

Portanto, as relações contratuais acabam sendo preferidas por garantir a entrega da matéria-prima. Essa constatação também é corroborada pelo autor, que defende a utilização das relações contratuais formais, ou seja, aquelas mais próximas das estruturas hierárquicas quando se observa alto nível de especificidade de ativos. Isso porque essas relações fogem dos custos das hierarquias e protegem os direitos de propriedade frente ao alto grau de dependência bilateral que existe nessas circunstâncias. As implicações operacionais das estruturas de governança são sintetizadas no Quadro 4, envolvendo: função; investimento; controle; programação da colheita; responsabilidade no processo; incertezas; conflito. 
Quadro 4. Estruturas de governança e suas implicações operacionais nas destilarias.

\begin{tabular}{|c|c|c|c|c|}
\hline Implicações & $\begin{array}{l}\text { Contrato de parceria } \\
\text { do tipo arrendamento }\end{array}$ & Integração vertical & $\begin{array}{c}\text { Contrato de } \\
\text { parceria agrícola e } \\
\text { de fornecimento }\end{array}$ & Mercado \\
\hline Função & $\begin{array}{l}\text { Garantia de matéria-prima } \\
\text { e opção de expansão }\end{array}$ & $\begin{array}{l}\text { Aproveitamento de } \\
\text { recursos (terra própria) } \\
\text { e garantia de matéria- } \\
\text {-prima }\end{array}$ & $\begin{array}{l}\text { Garantia de matéria- } \\
\text {-prima e ampliação da } \\
\text { capacidade }\end{array}$ & $\begin{array}{l}\text { Complementa a } \\
\text { produção }\end{array}$ \\
\hline Investimentos & Elevado & Muito elevado & Médio & Baixo \\
\hline Controle & Elevado & Muito elevado & Médio & Baixo ou Inexistente \\
\hline Programação da colheita & Maior & Maior & $\begin{array}{l}\text { Menor (dependência } \\
\text { do contratado) }\end{array}$ & $\begin{array}{l}\text { Não faz parte da } \\
\text { programação }\end{array}$ \\
\hline $\begin{array}{l}\text { Responsabilidade no } \\
\text { processo }\end{array}$ & Total & Total & Parcial & Nenhuma \\
\hline Incertezas & Não compartilhadas & Não compartilhadas & Compartilhada & Não compartilhada \\
\hline Conflito & Ausente & Ausente & Presente & Ausente \\
\hline
\end{tabular}

\subsection{Recursos estratégicos no setor alcooleiro}

No setor alcooleiro, os recursos e capacidades estratégicos capazes de gerar vantagem competitiva para as destilarias estão mais relacionados à localização e à distância média das propriedades contratadas. A capacidade de expansão, devido à fertilidade do solo, abundância de áreas mecanizáveis e ausência de competidores, bem como transparência, reputação, fidelidade e conhecimento também foram destacados.

Em relação à localização e distância, os gerentes e produtores entrevistados foram unânimes ao destacar a influencia desses recursos sobre a decisão de contratar. Isso porque a distância afeta tanto os custos de transporte da cana-de-açúcar até a unidade processadora quanto a qualidade da cana, que perde sacarose a partir do momento em que é queimada, sendo crucial o seu tempo-médio de chegada. Além disso, a localização é decisiva porque determina a topografia e qualidade da terra e os tipos de estradas disponíveis para o transporte (terra/asfalto). Nesse sentido, os contratos, os custos e os lucros resultantes são estabelecidos com os proprietários de terras a partir de condições estruturais da propriedade, determinadas pela sua localização, e da distância média da unidade processadora.

No caso das destilarias investigadas, os recursos estratégicos indicados, relacionados à locali- zação e à distância, estão diretamente associados à especificidade de ativos locacional e temporal, respectivamente, corroborando a complementaridade entre recursos estratégicos e ativos específicos, defendida por Combs e Ketchen (1999). Desse modo, é possível ratificar que a noção de especificidade de ativos é necessária à consideração de recursos estratégicos. Isso porque, enquanto a VBR se preocupa com a identificação de recursos estratégicos, a ECT discute o gerenciamento e captura de valor desses recursos (COMBS e KETCHEN, 1999).

A partir da complementaridade das abordagens, é possível tratar os recursos estratégicos como ativos específicos e considerar questões relacionadas à possibilidade de comportamento oportunista. Dessa forma, os recursos estratégicos, relacionados à localização e distância, só são capazes de trazer vantagens competitivas sustentáveis para as destilarias se possibilitarem a criação ou captura de valor. Nesse sentido, as destilarias realizam os contratos definindo cláusulas que comprometem as partes a cumprirem o acordado, com penalidades dispendiosas para quem não o fizer, tendo em vista que transacionam em condição de alta especificidade (locacional, temporal, de ativos físicos e dedicados).

Além da distância e da localização, os gerentes apontam a capacidade de expansão como 
fator diferencial. Essa capacidade se deve pela fertilidade do solo, abundância de áreas mecanizáveis e ausência de competidores. Nota-se que a proposta de David Ricardo (SAES, 2009) sobre as rendas ricardianas, na redução dos custos ou ampliação dos ganhos, se relaciona diretamente à vantagem competitiva advinda, neste caso, da capacidade de expansão pela fertilidade do solo e abundância de áreas mecanizáveis. A busca do controle de recursos, nessas condições, se justifica pela eficiência obtida e pelos ganhos resultantes.

Todos os entrevistados chamam a atenção para a importância da transparência, da reputação e da fidelidade que as partes devem construir para a boa continuidade das transações. Como a presença desses recursos estratégicos traz a diminuição da possibilidade de comportamento oportunista e apropriação de quase renda, as estruturas de governança são afetadas. Nesse sentido, a relação contratual, como opção à integração vertical, mostra-se satisfatória para garantir que não ocorra a perda do valor econômico nas transações realizadas nas destilarias, conforme destacado por Mérnard. (2002). Além disso, a posse desses recursos está associada à frequência na realização das transações, atributo analítico na ECT, e à existência de path dependencies (TEECE, PISANO e SHUEN, 1997), pelo lado da VBR.

É válido destacar que, apesar de apresentarem convergência quanto à consideração da distância e da localização como diferencial competitivo, as destilarias apresentam particularidades, denotando heterogeneidade nos seus recursos estratégicos e ativos específicos. Isso porque, enquanto algumas das destilarias apresentam como diferencial competitivo a menor distância média, outras apresentam a localização logística favorável ou, até mesmo, aspectos relacionados à capacidade de expansão e tradição no mercado. Portanto, pode-se constatar que diferentes especificidades de ativos (ECT) existentes entre as destilarias também explicam a sua heterogeneidade (VBR), o que Saes (2009) destaca como um ponto complementar entre as abordagens. Além disso, percebe-se que essas condições estabelecem diferentes custos de produção e de transação, o que reforça a heterogeneidade dessas organizações. Dito de outra forma, ativos específicos caracterizam recursos e capacidades que, apresentando diferentes condições, influenciam a configuração das estruturas de governança e a dinâmica da competição.

\subsubsection{Estruturas de governança e recursos estratégicos}

A partir das informações obtidas, percebeu-se que os recursos estratégicos apontados nas destilarias estudadas influenciam a configuração das estruturas de governança utilizadas. Conforme a classificação de Barney (1991), os recursos de capital físico relacionados à distância, localização, capacidade de expansão (fertilidade do solo, abundância de áreas mecanizáveis, ausência de competidores) e de capital organizacional, associados à transparência, reputação, fidelidade, tradição e conhecimento, afetam a forma como as partes envolvidas na aquisição de cana-de-açúcar transacionam. Além disso, notou-se que a escolha de um arranjo em detrimento de outro envolve mais do que uma questão de custos, uma vez que o conhecimento interno disponível na destilaria também se torna decisivo.

Diante desses recursos, a maior parte das entrevistas nas destilarias indicou que sua relação com os fornecedores se dá pela forma contratual, notadamente a parceria do tipo arrendamento. Considera-se que, nesse caso, o arrendamento caracteriza uma quase integração vertical, tendo em vista que, durante o período contratado, o arrendatário tem controle total sobre a propriedade. Como a distância e localização são recursos estratégicos para as destilarias alcançarem vantagens competitivas, o contrato de parceria do tipo arrendamento objetiva transações com proprietários de terras que atendam aos requisitos de proximidade, apresentem terras férteis e áreas adequadas ao plantio de cana-de-açúcar.

Percebe-se, então, que esse tipo de estrutura, do mesmo modo que a integração vertical, mostra-se capaz de sustentar e proteger vantagens competitivas advindas dos atributos dos 
recursos estratégicos da organização, relacionados à localização e distância, mas sem investimentos em imobilizado. Desse modo, conforme apontado por Saes (2009), é possível confirmar o aspecto complementar da VBR a partir da constatação de que a construção de capacidades e recursos distintos no tempo caracteriza direito de propriedade que necessita ser protegido pela integração vertical (Quadro 1).

Vale notar que o valor gerado pelos recursos estratégicos das destilarias permite ganhos adicionais relacionados à redução dos custos de transação pelo melhor gerenciamento das transações, que são baixos a partir dessa forma de estrutura. Com isso, é possível obter um controle maior e garantir a continuidade ou ampliação dos ganhos. Nesse raciocínio, enquanto o alinhamento entre atributos e estrutura gera eficiência, reduzindo custos de transação, recursos estratégicos podem criar valor para a organização, gerando capacidade competitiva. No caso das destilarias, esse tipo de arranjo se mostra válido, visto que os custos de transação gerados pela presença de ativos específicos são reduzidos pelos arranjos adotados, gerando condições para obtenção de maiores ganhos com a criação de valor obtida a partir dos recursos estratégicos.

Seguindo essa linha de raciocínio, os custos de transação existentes não justificariam por si só a estrutura de governança adotada. Essa é mantida porque, além de reduzir custos de transações, gera ganhos relacionados aos atributos presentes nos recursos controlados. Observa-se, portanto, o encontro da eficiência na gestão com a vantagem competitiva representada pela geração de renda superior aos concorrentes. Sendo assim, considera-se que a estrutura de governança mais presente, relacionada ao contrato de parceria do tipo arrendamento, é suficiente para tratar de duas questões fundamentais no campo de domínio da VBR e ECT: permite o controle de recursos estratégicos e a redução de custos de transação.

Os outros recursos estratégicos também influenciam e são influenciados pelas estruturas de governança adotadas. Como grande parte das transações é conduzida de modo transparente e calcada na reputação da destilaria e fidelidade das partes, problemas nas transações das destilarias com seus contratados dificilmente ocorrem. Isso pode se justificar porque, normalmente, é de interesse de ambas as partes manterem as relações contratuais por períodos de tempo mais longos. Nesse sentido, a estrutura de governança via contrato de parceria do tipo arrendamento mostra-se mais vantajosa para grande parte dos entrevistados. Além de trazer vantagens relacionadas ao controle do processo de plantio, manutenção de níveis de qualidade e produtividade e à programação de transporte e processamento, essa forma de governança pode propiciar proteção das relações, considerando-se a ausência de conflitos e a possibilidade de sustentação de vantagens competitivas.

No que diz respeito à influência do conhecimento, percebe-se que as destilarias apresentam maior domínio tecnológico sobre a cultura da cana-de-açúcar do que o produtor rural que, na maior parte das vezes, trabalha com diversificação de culturas. Por estarem na atividade há muitos anos, as destilarias se atualizam com maior rapidez e dominam o processo operacional e técnico empregado para plantio. Portanto, as capacidades internas relacionadas ao conhecimento sobre o cultivo de cana-de-açúcar mostram-se mais pertinentes do que a contratação externa, que normalmente depende de assessoria das destilarias. Além disso, a posse de equipamentos especializados por parte da destilaria gera maior efetividade e velocidade no plantio.

Essa constatação vem ao encontro da colocação de Williamson (2002 apud SAES, 2009) e Teece, Pisano e Shuen (1997) que admitem que a história da firma, o seu conhecimento e aprendizado, aspectos trabalhados pela VBR, influenciam na escolha de estruturas de governança adequadas, tratadas pela ECT. Portanto, a partir da aquisição do conhecimento de plantio e colheita e das capacidades operacional, técnica e financeira, conquistadas ao longo do tempo, as destilarias preferem adotar estruturas mais verticalizadas, que lhes possibilitam dominar o processo produtivo, como é o caso do contrato de parceria do tipo arrendamento. 
Além disso, a complementaridade torna-se clara a partir da constatação dos argumentos de Argyres e Zenger (2008), que defendem que a ECT fala diretamente da questão de como as firmas desenvolvem capacidades de maneira eficiente.

Por outro lado, essa situação traz como consequência direta a redução na transferência de conhecimento e sua concentração na destilaria. Isso porque o conhecimento é moldado a partir da estrutura de governança utilizada. Sendo assim, ocorre pouca transferência de conhecimento nos contratos de parceria do tipo arrendamento, uma vez que o proprietário ou produtor não participa da produção da cana-de-açúcar e não está em frequente contato com a destilaria. Uma relação de aprendizagem parece mais provável no caso do contrato de parceria agrícola, em que o proprietário ou produtor, por estar em constante interação com a destilaria e ser responsável pela produção, adquire conhecimentos técnicos e operacionais para a realização das atividades.

Vale ressaltar, ainda, alguns aspectos relacionados ao conhecimento técnico na escolha da estrutura de governança utilizada na colheita da cana-de-açúcar. A importância desse conhecimento no processo produtivo define, inicialmente, a escolha por relações contratuais, pela falta de capacidade interna das destilarias de realizarem o processo. Dito de outra forma, como os fornecedores desse tipo de serviço possuíam maior conhecimento sobre a sua execução, as destilarias contratavam seus serviços de colheita visando, em um primeiro momento, ter acesso a esses conhecimentos. Esse fator pode ser demonstrado na fala do gerente agrícola da Destilaria A: "Na colheita mecanizada [...]. Nós tínhamos recursos, na época era (sic) 10 milhões para fazer o investimento [...], o problema era como fazer aquilo ali funcionar. Ninguém tinha experiência de gerenciamento daquilo ali e, de operação, muito menos, ninguém sabia nada. Então, nós ficamos com receio de investir 10 milhões e não conseguir fazer aquilo lá andar. Aí nós terceirizamos".

Esse fator confirma alguns pontos de complementaridade das teorias ECT e VBR, quando se trata da eficiência e do controle de recursos.
Conforme destacado por Argyres e Zenger (2008), "as empresas governam internamente capacidades comparativas e terceirizam o acesso às capacidades onde a firma é comparativamente incompetente" (p. 6, tradução nossa). Complementa-se, dessa forma, a teoria da eficiência de Williamson (1985), observando-se que, neste caso, a destilaria troca o controle pelo incentivo do mercado, mas orientada pela noção de capacidade e não da redução de custos. Além disso, o argumento de Poppo e Zenger (1997) de que a escolha dos limites da firma define a posse e a composição dos recursos que a empresa possui também é confirmado.

Outro destaque relevante, nesse sentido, feito pelo gerente agrícola da Destilaria A, refere-se ao processo de aprendizagem sobre colheita mecanizada realizado pela empresa ao longo do tempo: "A gente não tinha (sic) conhecimento [...]. Em 2012, nós temos a intenção de adquirir a primeira máquina nossa [...], porque até 2015 o contratado vai estar aqui. Em 2012 eu coloco a máquina nossa só, e se ela der muito problema e a gente não conseguir (sic) trabalhar com ela, ela não vai atrapalhar o andamento da safra, porque os terceiros vão estar aqui. E eu tenho pessoas aqui do terceiro que sabem me ensinar a resolver o problema que eu tiver [...]".

Novamente a complementaridade entre a ECT e a VBR é encontrada a partir da afirmação de Langlois (1992) sobre os custos de governança dinâmicos. Ou seja, a destilaria alcançou aprendizado ao longo do tempo a partir de custos de informação ou conhecimento relacionados à transferência de capacidades dos contratados. Os argumentos de Argyres e Zenger (2008) também são admitidos, uma vez que a distribuição dos recursos nas destilarias no momento em que ocorreu a presente investigação, de fato, reflete uma série de decisões passadas que elas tomaram para desenvolver ou não capacidades internamente.

A adoção da integração vertical a partir de uma perspectiva de aprendizagem também encontra sustentação na afirmação de Goshal e Moral (1996), Poppo e Zenger (1997) e Argyres e Zenger (2008). Esses autores defendem que esse tipo de estrutura pode ser adotado pelo interesse 
da organização em desenvolver habilidades para tomar a iniciativa, para cooperar e para aprender. Dessa forma, a existência de ativos específicos causadores de comportamentos oportunistas não são a única explicação para a integração vertical.

Além do custo, do aprendizado e da capacidade superior do terceiro, os entrevistados destacam a divisão de responsabilidade, aspectos burocráticos e a confiabilidade como justificativa para a terceirização na colheita de cana-de-açúcar. Assim, a afirmação de Langlois (1992) de que as capacidades da empresa e do mercado, em conjunto com os custos de governança, determinam os limites da firma no curto prazo, é corroborada. Ainda, o raciocínio de Williamson (1985) de que a eficiência é o fator decisivo na escolha entre o mercado e a integração vertical traz complementaridade ao argumento de Saes (2009). Para a autora, as mudanças nessas estruturas dependem de um processo de realimentação, a partir do aprendizado e experiências pessoais dos gerentes sobre os custos de transação envolvidos.

Outro ponto de complementaridade refere-se ao controle, dadas as especificidades presentes (locacional, temporal, física, dedicada) e não apenas na vantagem estratégica da posse desses recursos. Além disso, devido ao controle, a estrutura de governança adotada garante a redução de comportamento oportunista face à condição de imobilidade imposta a esses recursos e permite, conforme destacado por Zylbersztajn (2009), que as respostas em condições de incerteza sejam mais rápidas.

Percebe-se, então, que a escolha por contratos de parceria do tipo arrendamento é justificada pelo controle e proteção de recursos estratégicos específicos relacionados à distância, localização, capacidade de expansão (fertilidade do solo, abundância de áreas mecanizáveis, ausência de competidores) e à transparência, reputação, fidelidade e tradição. Além disso, o conhecimento da destilaria normalmente prevalece sobre o do produtor, justificando a utilização dessa forma contratual.

O conhecimento sobre o processo de colheita mecanizada também influencia na escolha da estrutura de governança utilizada para realizar a colheita.
Isso porque a opção inicial prioriza a realização de contratos, na tentativa de apreender os recursos e capacidades dos terceiros, sendo que, em um segundo momento, percebe-se o interesse das destilarias em se integrar verticalmente para controlar o conhecimento advindo desse processo e gerar vantagens competitivas próprias. Nota-se que, embora inicialmente a função da colheita seja terceirizada, a responsabilidade pelos resultados e impactos desse tipo de atividade no segmento produtor ainda permanecem com a usina.

\subsection{Capacidade de resposta às questões ambientais}

A partir do exposto, foi possível compreender como as estruturas de governança adotadas pelas destilarias afetam a sua capacidade de resposta às leis ambientais. Conforme observado, as demandas ambientais inerentes às relações envolvendo os segmentos produtor e processador se associam, principalmente, à manutenção de reserva permanente e legal, e à realização de queimadas. A avaliação da capacidade de resposta às questões ambientais, objetivo desta seção, pode ser explicada pelas características e condições inerentes às estruturas de governança na consideração dos recursos e capacidades estratégicos. Nesse aspecto, busca-se um alinhamento entre a escolha da estrutura de governança, capaz de reduzir custos de transação e de sustentar vantagens competitivas, e a capacidade de atendimento das regras ambientais estabelecidas no ambiente institucional.

Como orientação, considera-se que os ativos específicos caracterizam recursos estratégicos para as destilarias, os quais precisam ser controlados para alcançar vantagens. O controle, nesse sentido, se relaciona diretamente à estrutura de governança escolhida, orientada pela busca de eficiência. Esse controle pode apresentar dois efeitos causais positivos: de um lado, visa reduzir custos operacionais e de transação; de outro, permite potencializar o atendimento das demandas ambientais, a partir do domínio de recursos e capacidades estratégicos relacionados. Dito de outra 
forma, o controle dos recursos permite minimizar gargalos produtivos, transacionais e ambientais. Isso porque, com a adequação entre estruturas e atributos presentes, ocorre uma redução dos conflitos nas relações e alinhamento nas decisões, os quais se associam, muitas vezes, às questões de ordem ambiental. Como consequência, esse alinhamento a partir dos atributos presentes pode indicar vantagens para estruturas que tendem à integração vertical, e se traduzir em eficácia no tratamento de questões ambientais.

A partir do estudo realizado, observou-se que as estruturas que possibilitam acelerar a capacidade de resposta das destilarias às imposições legais ambientais são a integração vertical e o contrato de parceira do tipo arrendamento. Como as destilarias já têm conhecimento sobre as leis ambientais instituídas e o pessoal técnico para a sua operacionalização, esses tipos de arranjos organizacionais possibilitam a elas obter o controle necessário para uma rápida implementação.

No caso do contrato de parceria agrícola e fornecimento, em que o produtor ou proprietário é o principal responsável pelo processo produtivo, a capacidade de resposta depende da articulação das partes envolvidas, o que pode demandar mais tempo. Nesses tipos de arranjos organizacionais, os gerentes agrícolas entrevistados confirmam que as principais dificuldades são corresponsabilidade e a ausência de direito de controle sobre o processo produtivo, que podem gerar custos de transação ou ineficiência. Isso porque podem ocorrer conflitos das destilarias com os produtores em função das decisões que precisam ser tomadas conjuntamente durante o processo produtivo.

Por outro lado, sob a perspectiva dos produtores, as estruturas que possibilitam maior capacidade de resposta às leis ambientais são o contrato de parceria agrícola, seguido pelo de fornecimento, em que eles têm na destilaria suporte e apoio necessários para o cumprimento das leis. É válido notar que esse fator intensifica ainda mais a relação de dependência entre o parceiro agrícola e o fornecedor com a destilaria. $\mathrm{O}$ surgimento de leis, que trazem consigo a necessidade de conhe- cimentos específicos e altos investimentos em tecnologia para sua implementação, gera uma situação de desvantagem e dependência do pequeno produtor rural frente à destilaria.

Como o pequeno produtor não apresenta capacidades internas suficientes para responder de forma imediata, a relação com a destilaria permite que essas capacidades sejam compartilhadas e a geração e exploração dos recursos estratégicos pode acontecer. Levando-se em consideração que o setor alcooleiro no Paraná é predominantemente caracterizado pela presença de pequenos produtores, essa condição de dependência foi fortemente observada. Esse fator também pode estimular a preferência por contratos de parceria do tipo arrendamento, que já se constituem como o principal arranjo utilizado pelas destilarias paranaenses. Outro ponto destacado pelos entrevistados diz respeito ao porte da empresa e à força política, em relação aos proprietários de terras e contratados, como fatores facilitadores nas negociações referentes às leis ambientais. Portanto, a velocidade de resposta se apresenta tanto na capacidade operacional da destilaria quanto na sua força política, que influencia positivamente os efeitos resultantes de um problema ambiental.

No que se refere à averbação de reservas, permanente e legal, independente da estrutura de governança utilizada, a resposta da usina para as leis ambientais depende do produtor proprietário, podendo ocorrer apenas transferência de conhecimento da destilaria acerca do como realizar os procedimentos necessários. Do mesmo modo, na relação via mercado, essa responsabilidade não é compartilhada com a destilaria. Isso significa que a resposta à demanda ambiental está nas mãos do produtor independente, sendo que a decisão de como e quando atender a legislação depende do mecanismo de enforcement existente. Nesse sentido, a destilaria não determina a necessidade de averbação na compra via mercado, visto que não há relação contratual durante a realização do plantio e da colheita da cana. Entretanto, a averbação se estabelece como condição geral para que a transação ocorra, uma vez que a queimada só pode acontecer com liberação 
do IAP, sendo possível apenas mediante apresentação de documentação de averbação de reservas permanentes e legais.

Já no caso das queimadas e utilização da vinhaça, a responsabilidade é da destilaria, apesar de o produtor estar indiretamente envolvido no processo. Nesse caso, as destilarias respondem mais rapidamente às exigências legais do que se tratando das reservas. Isso porque a capacidade da destilaria em termos de recursos e conhecimento operacional, legal e ambiental permite que essas ações sejam executadas dentro dos padrões estabelecidos. Além disso, mesmo no caso de ocorrências ambientais, as capacidades existentes na destilaria permitem melhor encaminhamento e solução para o problema. Na Figura 3 são sintetizados os resultados encontrados a partir das categorias de estudo configuradas.

Figura 3. Resultados a partir das categorias de análise.

\section{Custos de transação}

- Alta frequência.

- Incerteza: preços, fator climático, outras culturas, políticas agrícolas.

- Especificidade de ativos locacional, temporal, física, dedicada e humana. - Possibilidade de comportamento oportunista: pagamento, localização e queima proposital.

- Racionalidade Limitada: conhecimento sobre o mercado (produtor e processador) e conhecimento sobre o processo produtivo (produtor).

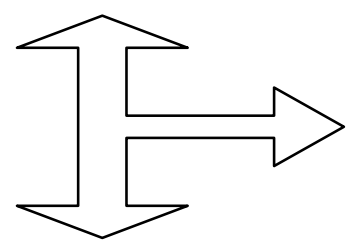

\section{Recursos estratégicos}

- Localização..

- Distância.

- Capacidade de expansão.

-Fertilidade do solo

-Abundância de áreas

mecanizáveis

-Ausência de competidores

- Transparência.

- Reputação.

- Fidelidade.

- Tradição.

- Conhecimento.

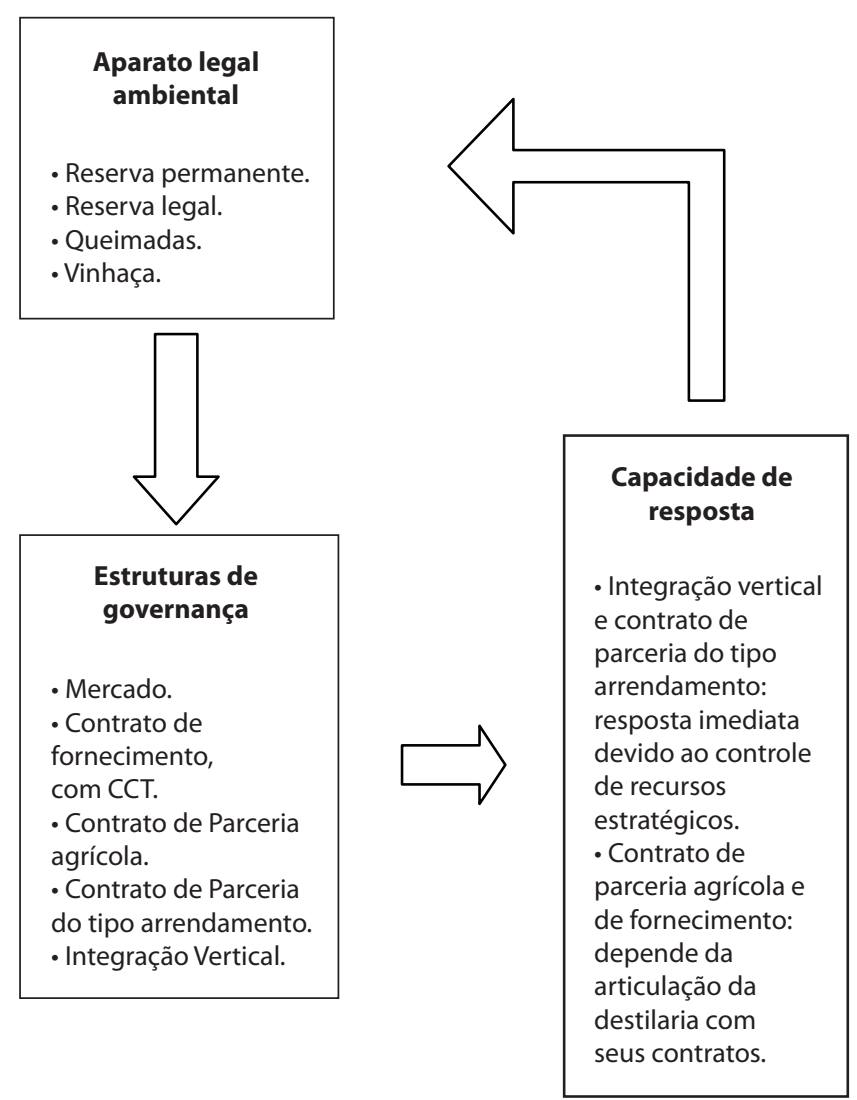




\section{Considerações finais}

O objetivo do presente estudo foi compreender como as estruturas de governança, configuradas por recursos e capacidades diferenciadas, podem afetar a capacidade de resposta aos estímulos impostos pelo aparato legal ambiental, nas relações de produtores e processadores, em destilarias no Paraná. Em relação às estruturas de governança, foram encontrados os três tipos identificados na literatura: integração vertical, contratos e mercado. No entanto, em todas as destilarias investigadas, percebeu-se forte tendência para a utilização de estruturas mais verticalizadas, isto é, que propiciam maior controle às destilarias. Essas estruturas se dão, em sua grande maioria, por meio de parceria do tipo arrendamento (contrato formal). A principal vantagem relatada está na obtenção de controle total, que permite às destilarias melhor planejamento e gerenciamento.

Em relação aos recursos estratégicos capazes de gerar vantagem competitiva para as destilarias, a localização da matéria-prima e a distância média das propriedades contratadas foram os mais citados. Além desses, a capacidade de expansão da produção da matéria-prima, devido à fertilidade do solo, abundância de áreas mecanizáveis e ausência de competidores, além da transparência, reputação, fidelidade, tradição e conhecimento, que foram outros recursos estratégicos identificados.

Ao se considerar as estruturas de governança identificadas, as informações obtidas permitem as seguintes afirmações: na integração vertical e no contrato de parceria do tipo arrendamento, o rápido atendimento às questões ambientais é possibilitado pela existência e controle de recursos e capacidade diferenciados; no contrato de parceria agrícola e de fornecimento, a capacidade de resposta envolve a competência de articulação da destilaria com seus contratados; na relação via mercado, a destilaria não está envolvida no atendimento às questões ambientais, que depende dos mecanismos de enforcement existentes, uma vez que o produtor realiza sua produção de modo independente (nesse caso, a relação se estabelece na compra de uma matéria-prima e não há envolvimento da destilaria na produção). Por outro lado, sob a perspectiva do produtor, a estrutura de governança via contrato de parceria agrícola viabiliza uma resposta mais rápida, visto que possibilita o suporte necessário para o cumprimento das leis.

A partir dos dados coletados, foi possível perceber a complementaridade entre a ECT e a VBR na explicação da configuração de estruturas de governança no setor alcooleiro paranaense. Isso porque a escolha das destilarias em realizar elas mesmas o plantio e a colheita se dá por conta de suas capacidades internas que, na maior parte das vezes, são superiores às dos contratados. Além de proteger os ativos específicos e recursos estratégicos contra comportamentos oportunistas, a relação contratual mais verticalizada permite às destilarias o controle necessário para explorar e obter vantagens competitivas a partir desses fatores e atender mais rapidamente as questões ambientais.

No entanto, é válido destacar algumas questões que indicam limitações para o estudo. Uma delas refere-se aos sujeitos entrevistados. Dentre as sete destilarias presentes no Paraná, duas não foram investigadas. Quanto aos produtores, o fato de não serem entrevistados produtores independentes, os quais identificam a estrutura de governança via mercado, pode configurar limitação. Justifica-se, entretanto, que a ampliação no número de entrevistas e a obtenção de informações de produtores independentes provavelmente não modificariam os resultados alcançados no presente trabalho, embora pudessem acrescentar novos pontos de vista.

Porém, algumas possibilidades para futuras pesquisas são vislumbradas. Uma possibilidade é a realização de estudos nas usinas de açúcar e álcool paranaenses. Contrastar ou complementar o presente estudo com a realidade de usinas de açúcar e álcool, que são empresas maiores, pode ser válido para denotar especificidades e os impactos do porte da empresa sobre as estruturas de governança empregadas. Outra sugestão é replicar o estudo em outros estados fabricantes 
de álcool no Brasil para confrontar as diferenças existentes entre diferentes regiões produtoras e suas justificativas. Perspectivas adicionais relacionadas à complementaridade da ECT com a VBR em outros setores agroindustriais também tornam-se importantes para efetivar as possibilidades de conexão entre essas abordagens, além de possibilitar o avanço na discussão teórica.

\section{Referências bibliográficas}

ALCOPAR Associação de Produtores de Bioenergia do Estado do Paraná. Banco de Dados Alcopar Maringá - PR. Disponível em: <www.alcopar.org.br>. Acesso em: 15 mar. 2010.

ARGYRES, N.; ZENGER, T. Capabilities, Transaction Costs, and Firm Boundaries: A Dynamic Perspective and Integration. Social Science Research Network (SSRN). Available at SSRN: <http://ssrn.com/ abstract $=1081857>$. Jun/2008.

BARDIN, L. Análise de Conteúdo. Lisboa: Edições 70, 2004.

BARNEY, J. Firm resources and sustained competitive advantage. Journal of management, v. 17, n. 1, p. 99-120, 1991.

CÓDIGO FLORESTAL. PRESIDÊNCIA DA REPÚBLICA FEDERATIVA DO BRASIL. Lei $n^{-} 4.771$, de 15 de Setembro de 1965. Disponível em: <www.planalto. gov.br>. Acesso em: 22 jan. 2010.

COMBS, J. G. e KETCHEN, D. J. Explaining Interfirm Cooperation and Performance: Toward a Reconciliation of Prediction from the Resource-Based-View and Organizational Economics. Strategic Management Journal, v. 20, p. 867-888, 1999.

FOSS, K. e FOSS, N. J. Assets, Attributes and Ownership. Journal of the Economics of Business, v. 8, n. 1, p. 19-37, 2001.

FOSS, K. e FOSS, N. J. The Next Step in the Evolution of the VBR: Integration with Transaction Cost Economics. Management Revue, v. 15, n. 1, mar. 2004.

GHOSHAL, S. e MORAN, P. Bad for Practice: A Critique of the Transaction Cost Theory. Academy of Management Review, v. 21, n. 1, p. 13-47, 1996.

INSTITUTO AMBIENTAL DO PARANÁ - IAP. Legislação Ambiental. Disponível em: <www.iap. pr.gov.br>. Acesso em: 22 fev. 2010.
JACOBIDES, M. G. e WINTER, S. G. The Co-Evolution of Capabilities and Transaction Costs: Explaining the Institutional Structure of Production. Strategic Management Journal, v. 26, p. 395-413, 2005.

LANGLOIS, R. N. Transaction-Cost Economics in Real Time. Oxford Journal - Industrial and Corporate Change, v. 1, n. 1, p. 99-127, 1992.

LANGLOIS, R. N. e FOSS, N. J. Capabilities and Governance: the Rebirth of Production in the Theory of Economic Organization. In: Danish Research Unit for Industrial Dynamics. January, 1997.

LINS, C. e SAAVEDRA, R. Sustentabilidade Corporativa no Setor Sucroalcooleiro Brasileiro. In: Fundação Brasileira para o Desenvolvimento Sustentável - FBDS. Rio de Janeiro: Agosto, 2007.

MÉNARD, C. The economics of hybrid organizations. Journal of Institutional and Theoretical Economics, p. 345-376, 2004.

MINTZBERG, H. et. al. Safári de Estratégia. Porto Alegre: Bookman, 2000.

MIZUMOTO, F. M. e ZYLBERSZTAJN, D. A coordenação simultânea de diferentes canais como estratégia de distribuição adotada por empresas da avicultura de postura. Organizações Rurais \& Agroindustriais, Lavras, v. 8, n. 2, p. 147-159, 2006

NORTH, Institutions. Journal of Economic Perspective, v. 5, n. 1, p. 97-112, Winter, 1991.

PENROSE, E. T. The theory of the growth of the firm. New York: Wiley, 1959.

PETERAF, M. A. The cornerstones of competitive advantage: a resource based view. Strategic Management Journal, v. 14, p. 179-191, 1993.

POPPO, L. e ZENGER, T. Testing alternative theories of the firm: transaction cost, knowledge-based, and measurement explanations for make-or-buy decisions in information services. Strategic Management Journal, v. 19, p. 853-877, 1998.

SAES, M. S. M. Estratégias de diferenciação e apropriação da quase-renda na agricultura: a produção de pequena escala. São Paulo: Annablume, Papesp, 2009.

TEECE, D., PISANO, G. e SHUEN, A. Dynamic capabilities and strategic management. Strategic Management Journal, v. 18, n. 7, p. 509-533, 1997.

UNIÃO DA INDÚSTRIA DE CANA-DE-AÇÚCAR UNICA. Sustentabilidade - Meio Ambiente. Disponível em: <www.unica.com.br/content>. Acesso em: 05 abr. 2010. 
WILLIAMSON, O. E. The economic institutions of capitalism: firms, markets, relational contracting. New York: Free Press, 1985.

WILLIAMSON, O. E. The mechanisms of governance. New York: Oxford University Press, 1996.

ZYLBERZTAJN, D. Papel dos contraltos na coordenação agro-industrial: um olhar além dos mercados. In:
SOUZA, J. P. de e PRADO, I. N. do (Org.). Cadeias produtivas: estudos sobre competitividade e coordenação. 2. Ed. Maringá: EDUEM, 2009.

ZYLBERSZTAJN, D. e SZTAJN, R. D. Análise econômica do direito e das organizações. In: (Org.). Direito e economia: análise econômica do direito e das organizações. 2. ed. Rio de Janeiro: Elsevier, 2005. 